\title{
Corpo e Psiquismo: sobre uma antinomia da experiência na obra de Freud
}

\author{
Body and psychism: on an antinomy \\ of experience in the work of Freud
}

\section{Eduardo Ribeiro da Fonseca*}

Pontifícia Universidade Católica do Paraná (PUCPR), Curitiba, PR, Brasil

\section{Resumo}

O ponto de vista psíquico domina a obra de Freud, dados os objetivos clínicos do autor, que desenvolve um método para tratar as neuroses de transferência no âmbito individual e atual. No entanto, a consideração do corpo como um organismo (Organismus) se faz necessária, o que implica, por outro lado, na consideração da série histórica dos indivíduos no contexto da Humanidade não apenas atual, mas também da série orgânica, o que resulta na consideração biológica e não apenas cultural. Essa é uma constatação que nos leva, curiosamente, à situação paradoxal na qual tanto o cérebro é tomado como um produto psíquico, como o psiquismo é tomado como um produto do cérebro.

Palavras-chave: Corpo. Psiquismo. Antinomia. Experiência. 


\section{Abstract}

The psychic point of view dominates the work of Freud, given the author's clinical objectives, which develops a method for treating transference neurosis in the individual person and the present context. However, the consideration of the body as an organism (Organismus) is necessary, which implies, on the other hand, the consideration of the historical series of individuals in the context of Humanity not only current but also of the organic series, which results in a biological and not just cultural point of view. This is a finding that leads us, curiously enough, to the paradoxical situation in which both the brain is taken as a psychic product, as the psychism is taken as a product of the brain.

Keywords: Body. Psychism. Antinomy. Experience.

\section{Introdução}

Em nosso livro Uma estreita passagem: sobre o conceito de corpo nas obras de Schopenhauer e Freud (2016) empreendemos a difícil tarefa de abordar o conceito de corpo na obra do psicanalista vienense que, ao contrário do que faz Schopenhauer com o Leib, não o situa diretamente como noção filosófica, mas sim como noção operatória em função de seus interesses ligados mais diretamente ao desenvolvimento psíquico. Essa peculiaridade da obra do psicanalista tornou necessária uma abordagem que, de certa forma, deixa muitos pontos obscuros a serem abordados, especialmente no que concerne à paradoxal oposição entre o organismo como fato biológico e o corpo erógeno tomado como realidade psíquica. Por mais que Freud fale do corpo como um Organismus e que essa consideração do corpo biológico seja sempre recorrente desde as primeiras elaborações dos anos 1880 e 90, ela é também bastante problemática do ponto de vista filosófico. Nesse contexto, o mundo é, ao mesmo tempo, uma coisa perene da qual o organismo finito participa e algo que só adquire sentido para uma consciência perceptiva individual que estabelece relações entre as coisas e se distingue a partir da distinção gradual entre a sua própria existência e a de um mundo exterior, dada principalmente a partir das sensações corporais (FREUD, SA III, 1923, 
p. 294). A consideração de que existe uma fronteira tênue entre o que caracteriza um indivíduo avaliador dotado de autoconsciência, de um Eu, o seu corpo orgânico e o objeto representado traz um problema que, do ponto de vista de Freud, precisa ser considerado a partir de determinadas hipóteses sobre o próprio organismo. O corpo próprio, nesse contexto, é significado pelo sujeito da consciência, pelo Eu, através da comparação de sua atividade orgânica, que se apresenta para a percepção na forma de dados constantes da série prazer-desprazer, com aqueles dados evanescentes que se constituem apenas como a imagem de um mundo exterior ao corpo, ainda que, em seu conjunto, esses dados exteriores se deem também como uma exigência permanente de atividade na série da necessidade (FONSECA, 2016, p. 112).

O nosso propósito neste presente artigo é discutir um problema específico relacionado a esse contexto, desdobrado a partir de dois contextos diferentes, de acordo com uma perspectiva schopenhaueriana. A saber, por um lado, (1) a análise e a crítica feitas por Schopenhauer das antinomias kantianas e o seu significado para o problema do corpo como um Organismus em Freud, e, por outro lado, (2) a análise e a crítica do materialismo, especialmente o materialismo biológico de Lamarck, e suas consequências para a consideração do Organismus do ponto de vista evolucionário em Freud. É nesse contexto que debateremos as consequências dessas análises do ponto de vista de uma possível antinomia freudiana.

\section{Schopenhauer, as antinomias kantianas e o problema da realidade psíquica em Freud}

Falar sobre a experiência psíquica do corpo e da materialidade do mundo em Freud é uma missão das mais ingratas, pois, de certa forma, através dela, sou obrigado a reabrir velhos caminhos espinhosos trilhados antes pela filosofia de Kant e por Schopenhauer e apenas depois pelo psicanalista, cada um deles à sua própria maneira e perseguindo os seus próprios objetivos (Kant o caminho de sua crítica, Schopenhauer o de sua metafísica da Vontade, e Freud a sua clínica e a metapsicologia a ela 
associada). Tais caminhos elevam extraordinariamente a tensão do pensamento e nos conduzem, muitas vezes, às regiões mais obscuras da lógica, onde a razão se mostra relativamente incapaz, regiões essas onde o pensamento perde a sua desejada consistência e adquire um caráter mais especulativo, em relação ao qual a experiência, que é, segundo pensamos, a única fonte e ponto de partida para o pensamento, torna-se cada vez mais rarefeita, engendrando o conflito insolúvel, paradoxal, entre duas ideias opostas consideradas igualmente racionais.

Seguindo essa perspectiva do pensamento, se aceitamos a distinção entre erro e ilusão proposta por Schopenhauer, a ilusão seria então uma coisa da experiência da percepção e, como tal, poderia ser corrigida, enquanto o erro seria algo relacionado ao mau uso da racionalidade, o que, para o filósofo de Danzig, implicaria na utilização de conceitos que nos afastam da experiência possível e que entram de assalto na experiência propriamente dita como ideias reguladoras, mas que, num certo sentido, conduzem o pensamento a uma ordem prescritiva e, por outro lado, impedem o avanço do próprio pensamento no sentido de corrigir o erro. É por isso que o filósofo de Danzig, em sua obra mais tardia, vai dizer que é justamente nos conceitos que os erros da Humanidade se abrigam e se preservam através das gerações. Sendo assim, lidar com esse tipo de construção racional, que, no entanto, está desapegada da experiência possível, pode nos conduzir, e em geral nos conduz, a meras fantasmagorias teóricas, a jogos mentais, a emaranhados de conceitos considerados muito elevados, mas que, no fim, apenas fazem com que a própria razão se afaste cada vez mais da experiência.

\section{Schopenhauer, Lamarck e as "fantasias científicas" de Freud}

É justamente ao pensarmos o problema das quatro antinomias kantianas, cujas teses são sempre ideias incondicionadas da razão e cujas antíteses são sempre empíricas, que esse problema se evidencia, pois estamos, no fundo, questionando a cientificidade das noções freudianas acerca do corpo e do psiquismo, que transitam entre a herança arcaica de caracteres não apenas biológicos, mas também do ponto de 
vista da espontaneidade do psiquismo, e, por outro lado, da capacidade das representações inconscientes de moldarem o próprio psiquismo, mas, inclusive, o próprio orgânico, especialmente no que tange à herança de características e o efeito das condições psíquicas originárias da Humanidade sobre todas as gerações subsequentes, como que moldando o psiquismo humano em suas estruturas fundamentais. Especialmente a ideia de fixação de características no âmbito da filogênese e também no âmbito atual que corresponde à história do indivíduo determinado e, notem bem, a possibilidade de um retorno do indivíduo a esses pontos de fixação é uma hipótese científica extremamente ousada, inspirada de modo evidente nas ideias de Lamarck. Freud escreve sobre isso a Abraham, em 2 de novembro de 1917. Reparem nas palavras do psicanalista vienense:

O propósito é colocar Lamarck completamente em nosso terreno, e mostrar que a sua "necessidade" [besoin], que forma e transforma os órgãos não é outra coisa senão o poder da representação inconsciente sobre o nosso próprio corpo, da qual encontramos restos na histeria, em uma palavra, a onipotência dos pensamentos. Dessa maneira ficaria psicanaliticamente explicada a finalidade [teleologia]; seria a completude da psicanálise (FREUD, 1987, p. 111).

Esta surpreendente concepção é uma espécie de releitura do capítulo dos "Complementos" de 1844 de O mundo como vontade e representação (1819) que se chama "Sobre a teleologia" (SCHOPENHAUER, 2014, p. 475), mas, com o acréscimo dessa interessantíssima concepção do "poder da representação inconsciente". Mas, há também uma incômoda questão de fundo no que concerne a essas "fantasias" de Freud (Carta de Freud a Fliess de 05 de outubro de 1895; FREUD, 1987), a saber, a sua cientificidade, o que, na linguagem freudiana significa especialmente o seu grau de conexão com a experiência ${ }^{1}$. A "fantasia científica" é racional, mas qual a sua efetividade?

Em Acha (2007, p. 121), encontramos o seguinte comentário sobre as "fantasias" lamarckistas de Freud: "0 projeto de investigação navega na ambiguidade de uma narrativa geral do devir humano que inclui uma teoria do progresso e um marco conceitual desejado para a psicanálise. A 'fantasia filogenética' é o modo de compreender uma dialética da cultura 


\section{Experiência, intuição empírica e conceito na crítica de Schopenhauer a Kant}

Neste sentido, retornamos a uma crítica de Schopenhauer a Kant. Segundo Cacciola, o primeiro questiona a definição de razão dada pelo segundo, segundo a qual a razão seria a "faculdade de princípios" (SCHOPENHAUER, 1991, p. 138), que Kant contrapõe à de entendimento como "faculdade de regras" (CACCIOLA, 1981, p. 69). Segundo a autora, a distinção entre regras e princípios não está, na opinião de Kant, "no caráter de generalidade, nem na sua origem conceitual, mas na impossibilidade em que se encontra o entendimento de fornecer conhecimentos sintéticos a partir de conceitos, já que o uso do entendimento pressupõe sempre a intuição da qual resulta a percepção efetiva" (p. 69). Pensando o problema das quatro antinomias nesse contexto teríamos um resultado interessante.

A antinomia da razão pura é definida como o conflito entre as leis que governariam a razão pura. Tal conflito ocorreria quando a Vernunft tenta responder a questões que estão, por assim dizer, fora do campo da experiência possível. A síntese da experiência efetiva é feita a partir da intuição do mundo sensível pelo esquema transcendental da imaginação. A função do entendimento, nessa concepção, é fazer a síntese do esquema transcendental. É só então que a razão, já liberta das restrições da experiência possível, vale-se do incondicionado para fazer a síntese do conjunto da experiência efetiva. Ela faz, por assim dizer, um uso operatório da noção de ideia transcendental, que não é dada diretamente na experiência, mas sim naquilo que pode ser concebido pela razão de modo independente da experiência, proporcionando um acabamento à própria experiência indo além dela. É contra o uso desse recurso que Schopenhauer vai se rebelar no âmbito de sua própria filosofia, pois, para ele, o recurso de Kant ao incondicionado é contraditório.

Segundo Cacciola (1981, p. 68), Schopenhauer não aceita este caráter distintivo que, para Kant, define o princípio como "conhecimento sintético a partir dos conceitos" (KANT, B, 2016, p. 279), pois para ele,

de cujos efeitos a psicanálise pretende dar conta através do tratamento da neurose e particularmente certos aspectos da esquizofrenia, que o texto sobre o Presidente Schreber enuncia de maneira paradigmática (Freud, 1911c)." 
qualquer conhecimento sintético "a partir de meros conceitos é impossível" e "de meros conceitos nunca podem provir outras proposições, a não ser as analíticas" (SCHOPENHAUER, 1991, p. 183). Para Cacciola, "fica assim afirmado pelo filósofo kantiano o uso exclusivamente lógico da razão" (CACCIOLA, 1981, p. 69).

Por outro lado, as antinomias da razão não constituiriam uma efetiva luta da razão consigo mesma, mas apenas "um duelo aparente", uma luta diante do espelho (CACCIOLA, 1981, p. 71). Só as afirmações das antíteses são aceitas por Schopenhauer. A razão para isso é que ele as considera fundamentadas sobre as formas da faculdade de conhecimento, que, objetivamente, "corresponderiam às próprias leis universais da natureza" (CACCIOLA, 1981, p. 71; SCHOPENHAUER, 1991, p. 148). Para Cacciola, a partir dessa abordagem do problema do conhecimento da coisa em si que para o filósofo é o conhecimento da vontade, uma crítica da razão mediante "antinomias e sua solução para elas" é dispensável (CACCIOLA, 1981, p. 69). Bastaria, nesse caso, uma crítica da razão que investigue a relação "do pensamento abstrato ao imediatamente intuitivo" (p. 69). A concepção schopenhaueriana de razão não admite apenas princípios meramente lógicos. Para Schopenhauer, os princípios transcendentais da razão, tal como os define Kant são inaceitáveis e, além disso, fonte de um conflito insolúvel para o conhecimento.

No que concerne exclusivamente à terceira antinomia, Schopenhauer assevera que é a única que se refere, ainda que não nomeadamente, à distinção entre coisa em si (CACCIOLA, 1981, p. 71), no âmbito da liberdade incondicionada, que Schopenhauer vai traduzir pelo seu conceito de "liberdade da vontade", em oposição ao fenômeno, condicionado, e que o filósofo de Frankfurt vai traduzir pelo seu próprio conceito de "representação", lugar da ciência e fonte dos conhecimentos sintéticos, que, segundo ele, só podem provir da experiência, o que está explicitado, por exemplo, em seu belíssimo texto chamado "Sobre a necessidade metafísica da Humanidade" (SCHOPENHAUER, 2014, p. 249). 


\section{Lamarck, materialismo e animal originário}

Do ponto de vista do materialismo, Schopenhauer questiona Lamarck, pois, segundo ele, o naturalista teria cometido um "erro genial" (BRANDÃO, 2002, p. 365)², tomando algo objetivo como último fundamento de esclarecimento. Tal fundamento seria "a matéria (Materie), in abstracto, apenas como ela é pensada, ou aquela já penetrada pela forma, empiricamente dada, portanto, o material (Stoff) ${ }^{3 \prime}$ (BRANDÃO, 2002, p. 213). Schopenhauer, no entanto, elogia que o naturalista francês tenha compreendido bem que a "vontade do animal é o originário (Wille des Tiers das Urprüngliche ist) e o que há determinado a sua organização" (BRANDÃO, 2002, p. 213). Por outro lado, o filósofo deplora o fato de Lamarck aparentemente ter tomado "o corpo (Körper) como coisa-em-si" e o tempo e o espaço "como qualidades (Beschaffenhaiten) da coisa-em-si". Segundo o filósofo, o pensamento de Lamarck não havia "penetrado a grande e fecunda doutrina da idealidade do tempo e do espaço (Idealität des Raumes und der Zeit)", nem nada do que "nela está implícito". Por isso Lamarck "não pode conceber a constituição (Konstruktion) dos seres de outro modo senão por sucessão (Sukzession)" (SCHOPENHAUER, SW III, p. 409).

Para Schopenhauer, Lamarck não pode compreender que a vontade animal, como coisa em si, está fora do tempo, podendo ser, neste sentido, "mais originária (ursprünglicher) que o animal mesmo" (SCHOPENHAUER, SW III, p. 409). O mais originário, neste caso, é justaposto ao fenômeno caracterizado no tempo e no espaço, e não propriamente anterior, a não ser no sentido lógico, pois, senão, estaria fundamentado na sucessão. A penas o animal determinado é que é a expressão fenomênica dessa vontade, e, portanto, apenas ele está ligado à sucessão espaço-temporal (FONSECA, 2012, p. 154).

Lamarck, pelo contrário, escolhe a ordem temporal e concebe, a partir disso, um "animal sem órgãos decisivos, mas também sem tendências decisivas, dotado meramente de percepção" (Wahrnemung),

\footnotetext{
Brandão cita Sobre a Vontade na Natureza (SCHOPENHAUER, WN, SW III, p. 409).

Brandão cita O Mundo como Vontade e Representação (SCHOPENHAUER, WWV, SWI, p. 65).
} 
que, segundo Schopenhauer, ensina-lhe as circunstâncias em que tem que viver (tal discussão ressurge no Freud de 1920, já pensada dentro da nova ordem pulsional dualista que opõe vida e morte, e que toma a morte como o mais originário, ou, nas palavras de Schopenhauer, "o privilégio do primeiro ocupante"). Surgem de tal conhecimento as suas tendências, a saber, sua vontade. E desta, por fim, seus órgãos e sua corporização determinada, com a ajuda da geração e, por conseguinte, num imenso espaço de tempo (FONSECA, 2012, p. 154). Para Schopenhauer, se Lamarck tivesse

tido ânimo de para chegar até o fim, teria tido que supor um animal primitivo, o qual deveria ser sem figura nem órgãos, que, em virtude de circunstâncias climáticas e locais, teria se transformado nas miríades de espécies animais de toda classe, desde a mosca até o elefante (SCHOPENHAUER, WN, SW III, p. 366).

Mas, para o filósofo da Vontade, tal animal primitivo seria a vontade de viver, sendo, como tal, algo metafísico e não físico (SCHOPENHAUER, WN, SW III, p. 366), e é esse movimento do pensamento que Freud tenta completar aparentemente sem o recurso da metafísica, mas sim de uma metapsicologia.

Com isso, Freud parece haver feito a tentativa, em relação a Lamarck, por um lado, e a Schopenhauer, por outro, de transformar o princípio de organização seja como necessidade, seja como vontade, em uma auto-organização a partir da libido e do controle do acesso às representações pelo inconsciente que teria o poder de transformar não apenas o mundo externo, no sentido da cultura, mas também o mundo interno e o próprio corpo, no sentido de uma autoplástica.

\section{Uma possível antinomia freudiana}

Nesse sentido, a possível antinomia freudiana que gostaríamos de pensar aqui é a que se refere à oposição entre corpo e psiquismo, que pode ser enunciada da seguinte maneira: tanto é verdade dizer que todo o mundo percebido e experimentado pelo ser cognoscente depende do 
psiquismo, do aparelho anímico, um psiquismo inclusive capaz de produzir modificações no corpo ao longo do tempo, e que, até mesmo, do ponto de vista da representação, desaparecendo o psiquismo todo o universo desapareceria com ele, quanto é necessário igualmente admitir que esse ser cognoscente depende de toda uma cadeia de causas anteriores do qual ele é um pequeno elo, isto é, é preciso assumir ao lado do funcionamento psíquico uma ordem natural subjacente, da qual o corpo e o sistema nervoso fazem igualmente parte e da qual são indissociáveis, inclusive considerando o poder do inconsciente sobre o corpo, cujo exemplo na experiência na psicanálise pode ser dado pela histeria de conversão. Ambas as perspectivas se afirmam de modo independente e com igual direito, porém, são igualmente frágeis, ou, em termos lógicos, triviais, na medida em que, por um lado, o aparelho anímico é um postulado heurístico, uma maquinaria teórica que tem o propósito de tornar mais compreensível a complexidade de nosso funcionamento psíquico, o que nos seus limites excede o campo da experiência possível, a partir do que é criada por Freud uma Metapsicologia, e por outro, reforçamos, com igual direito, o corpo não pode ser tomado apenas como um produto do psiquismo, pois isso equivaleria a admitir que a ordem biológica em si mesma seria produzida pelo próprio psiquismo, o que, para Freud, é uma tese com um sentido metapsicológico específico exposto na carta a Abraham, mas que teria que ser muito bem provada, de um ponto de vista científico, sem recurso à metafísica da vontade schopenhaueriana, que, como vimos, postula um princípio metafísico, ainda que imanente. A tese de Freud, ressaltemos, coloca corpo e psiquismo lado a lado, como polaridades que tensionam o material e o imaterial na composição do mundo.

Restaria, portando, dessa equação, um paradoxo vivo, do qual não se poderia escapar, tal como nas antinomias kantianas, mas sem o recurso ao incondicionado. Do ponto de vista do que é possível conhecer, nós nos encontraríamos na situação circular na qual o psiquismo, a sensibilidade, a representação e o próprio organismo são produtos da atividade do sistema nervoso e, por sua vez, o sistema nervoso, o corpo e o mundo devam ser tomados simultaneamente como produtos psíquicos, dependendo da perspectiva adotada para pensar esses problemas que, de certa maneira, excedem a possibilidade de conhecimento 
empírico, ficando o psicanalista pendurado pelo fio da representação entre o corpo e o psiquismo. A fronteira entre as duas situações é indiscernível e há o agravante de que também as fronteiras entre o que é a "realidade psíquica" e o que é a efetividade são também mal definidas, ou seja, a feliz coincidência de sermos simultaneamente o observador e o observado nos conduz, porém, à dificuldade de termos que decidir o quanto poderíamos ou não confiar na objetividade de nossas conclusões em assuntos tão decisivos, mas que envolvem sem dúvida, desde a tradição cética, o questionamento da própria capacidade do sistema psíquico em escapar da ilusão e do erro.

Em sua 35 a das "Novas conferências introdutórias à psicanálise" (1933[1932]), "A questão de uma Weltanschauung", Freud argumenta que as ações de uma pessoa são "governadas por suas opiniões, por seu conhecimento". Nesse sentido, como ele escreve nessa conferência 35,

é o mesmo espírito científico que especula acerca da estrutura dos átomos, ou acerca da origem do homem, e que planeja a construção de uma ponte capaz de suportar uma carga. Se isso em que acreditamos fosse realmente coisa sem importância, se não houvesse aquilo que se chama conhecimento, e que se diferencia dentre nossas opiniões por corresponder à realidade, poderíamos construir pontes tanto com papelão, como com pedras, poderíamos injetar em nossos pacientes um decagrama de morfina, em vez de um centigrama, e poderíamos usar gás lacrimogêneo como anestésico, em lugar de éter. Mas os próprios anarquistas intelectuais rejeitariam tais aplicações práticas de sua teoria (FREUD, SA I, p. 603).

No entanto, tais argumentos não parecem suficientes para anular o fato de que na primeira parte da citação de Freud ele trata de "especulações", que, de certa forma, violentam o dado empírico em favor de uma concepção provisória fundada em conceitos heurísticos, em metáforas adequadas, que não podem ser objeto de intuição sensível. A segunda metade, referente à experiência, ao dado sensível, é tratada como ciência aplicada e estaria dentro dos limites de uma ciência kantiana sem metafísica. Teríamos então uma ciência que parte do condicionado, a fisiologia do organismo, para o incondicionado, o aparelho anímico, ou o contrário, criando uma possível antinomia. 
O conhecimento, nesse sentido, torna-se problemático, pois o objeto do conhecimento não apenas excede a possibilidade de conhecer, mas principalmente depende da realidade psíquica, da percepção que, por um lado, claramente distorce os dados e, por outro, completa as lacunas com ficções, o que não é de todo mau, se considerarmos ao menos que de certo modo Freud reconstrói em sua própria doutrina as críticas de Schopenhauer a Kant e Lamarck, incluindo talvez o próprio Schopenhauer nelas, mas, por outro lado, cai numa contradição que envolve a dificuldade de fundamentar a própria estrutura teleológica da teoria sem os recursos metafísicos transcendentes ou imanentes, por um lado, e sem a materialidade de Lamarck, por outro, já que a consideração da força do espiritual sobre o material fundamenta os argumentos metapsicológicos. A própria necessidade de avançar simultaneamente em todos esses terrenos expõe a dificuldade do psicanalista vienense com essa sua metapsicologia, sem dúvida um monumento genial ao pensamento, porém, tão inacabado quanto a catedral da Sagrada Família, projetada pelo catalão Antoni Gaudi em Barcelona.

É frente a esse tipo de dificuldade que Freud vai escrever o seguinte, ao final de seu manuscrito metapsicológico publicado recentemente, chamado Neuroses de transferência: uma síntese:

Fique evidente que com esses esclarecimentos [referindo-se ao próprio texto do manuscrito] não conseguiremos senão salvar nossas fantasias científicas da censura de que são absurdas. Em todo o caso, elas mantêm seu valor como desilusão saudável se, indo por esse caminho, pusermos a disposição filogenética acima de tudo. As coisas não se passam de maneira a que as constituições arcaicas retornem hoje em indivíduos, por exemplo, em proporções pré-estabelecidas, empurrando-os para a neurose através do conflito com as exigências atuais. Há lugar para novas aquisições e novas influências, as quais ainda não conhecemos. Contudo, não alcançamos o ponto final; antes, estamos no princípio de uma compreensão desses fatores genéticos (FREUD, 1987, p. 82).

A construção da antinomia entre corpo e psiquismo talvez seja tão insolúvel quanto a das antinomias kantianas porque, como vimos nas tentativas de Lamarck e Schopenhauer, por mais que estes pensadores tenham buscado estabelecer o nexo do mundo a partir de uma ordem 
natural em oposição à ordem teológica que fundamentava o criacionismo, por um lado, e o fixismo, por outro, ainda assim, justamente por isso, precisaram utilizar o recurso da matéria e da vontade, que, de um ponto de vista prático, substituem o incondicionado kantiano sem a vantagem do conforto psicológico, ou seja, da ordem cosmológica que precede a experiência e que lhe confere sentido transcendente.

Em Freud, é notório que o problema da corporeidade é tomado de um ponto de vista psíquico. Mas, também em seu caso, a metapsicologia parece tomar o lugar de uma ordem substituída por um princípio ordenador, que deixa as suas marcas a partir de pontos de fixação aos quais se retorna e, por outro lado, pressupõe as condições de possibilidade filogenéticas para o fenômeno atual que constitui o corpo, a libido, o desejo, o inconsciente substantivado ou qualitativo, as instâncias e estruturas psíquicas, e assim por diante.

Nesse caso, para completarmos nosso questionamento, retornamos ao solo kantiano, que justifica a construção de antinomias argumentando que ao pensar a totalidade do mundo a racionalidade é inevitavelmente conduzida a antinomias, isto é, à contradição consigo mesma. As tentativas malogradas de superar essa dificuldade racional são patentes nas cartas de Freud nas quais ele confronta a ciência dura e a fantasia especulativa. Em 8 de abril de 1915 (FREUD; FERENCZI, 1996, p. 55), Freud escreve a Ferenczi que o "mecanismo" da criatividade científica é um arranjo "entre o jogo audacioso da fantasia e a crítica implacável da realidade" (FREUD, 1987, p. 94). Cerca de três meses depois, em carta de 12 de julho de 1915 (FREUD, 1987, p. 60), Freud fala na tentativa de "domar com sacrifício inclinações especulativas, justamente porque se tratavam de fantasias. [...] Sustento que não se devam fabricar mais teorias - elas precisam entrar em nossas casas como visitantes não convidados, enquanto se está ocupado na pesquisa de pormenores." Elas entram como visitantes não convidados, mas, diríamos, até mesmo como hóspedes molestos. O incômodo é tanto que, diante da insistência com que Lou Andreas Salomé lhe pergunta sobre sua metapsicologia e lhe pede que envie para publicação seus novos artigos metapsicológicos supostamente já escritos, Freud responde, em 18 de março de 1919: “Onde está minha metapsicologia? Por enquanto continua a não ser escrita" (FREUD, 1987, p. 93). Mas, 
sabemos que nesse ano ele está em fase de elaboração do seu texto "Além do princípio de prazer", que não apenas dá acabamento à sua metapsicologia, mas a remodela em outras bases, sob a influência da leitura de Schopenhauer, que, no entanto, é desagradável pelo mesmo motivo que, muitos anos antes, em 1896, esquece o nome do pintor Signorelli, a saber, a necessidade de pensar o vínculo entre sexualidade e morte. Freud e toda a metapsicologia estão sob o efeito dessa questão e ela jaz, indelével, ao fundo da aqui mencionada "antinomia freudiana" entre corpo e psiquismo, num jogo de continuidade e descontinuidade entre fenômenos e ordens de fenômenos que perfazem as questões humanas fundamentais, para as quais nunca temos, de fato, respostas suficientemente boas e passíveis de serem construídas com boa lógica e racionalidade.

\section{Referências}

ACHA, O. Freud e o problema da história. Buenos Aires: Prometeo Libros Editorial, 2007.

BRANDÃO, E. O conceito de matéria na obra de Schopenhauer. Tese (Doutorado em Filosofia) - Universidade de São Paulo (USP), 2002.

CACCIOLA, M. L. A crítica da razão no pensamento de Schopenhauer. Dissertação (Mestrado em Filosofia) - Departamento de Filosofia, Universidade de São Paulo, São Paulo, 1981.

FONSECA, E. R. da. Psiquismo e vida: sobre a noção de Trieb nas obras de Freud, Schopenhauer e Nietzsche. Curitiba: Editora UFPR, 2012.

FONSECA, E. R. da. Uma estreita passagem: sobre o conceito de corpo nas obras de Schopenhauer e Freud. Curitiba: Editora UFPR, 2016.

FREUD, S. SA Die S Freud-Studienausgabe. (S. Fischer Verlag, 1980). Org. 2. ed. Munique: DTV/de Gruyter, 1999. 11 v. (As referências a essa edição são indicadas pelas iniciais SA, seguidas do número do volume em algarismo romano e do número da página em número arábico). 
FREUD, S. A correspondência completa de S. Freud para W. Fliess. Rio de Janeiro: Imago, 1986.

FREUD, S. Neuroses de transferência: uma síntese. Rio de Janeiro: Imago, 1987.

FREUD, S; FERENCZI, S. The Correspondence of Sigmund Freud and Sandor Ferenczi. Cambridge: The Belknap Press of Harvard University Press, 1996. v. 2, p. 1914-1919.

KANT, I. Crítica da razão pura. Trad. Fernando Costa Mattos. Petrópolis: Vozes, 2016.

SCHOPENHAUER, A. WWV Die Welt als Wille und Vorstellung, ["O Mundo Como Vontade e Representação" e "Complementos"] - 1819 (1. ed.); 1844 (2. ed.); 1859 (3. ed.). In: SW Sämtliche Werke. Wolfgang Frhr. von Löhneysen (ed.). Frankfurt: Suhrkamp Verlag, 1986. 5 v. (As referências a essa edição são indicadas pelas iniciais $S W$, seguidas do número do volume em algarismo romano e do número da página em número arábico).

SCHOPENHAUER, A. Crítica da filosofia kantiana. Trad. Maria Lúcia Cacciola. 5. ed. São Paulo: Nova Cultural, 1991. (Os Pensadores).

Recebido: 10/06/2018

Received: 06/10/2018

Aprovado: 19/06/2018 Approved: 06/19/2018 